\title{
Optimization of Agrobacterium tumefaciens-Mediated Genetic Transformation of Maize
}

\author{
Mengtong Liu ${ }^{1}$, Yangyang Zhou ${ }^{1}$, Tongyu Liu ${ }^{1}$, Jianyu $\mathrm{Lu}^{1}$, Jing $\mathrm{Qu}^{2}$, Shuyan Guan ${ }^{2, *}$ and Yiyong $\mathrm{Ma}^{2, *}$ \\ ${ }^{1}$ College of Life Sciences, Jilin Agricultural University, Changchun, 130118, China \\ ${ }^{2}$ College of Agronomy, Jilin Agricultural University, Changchun, 130118, China \\ *Corresponding Authors: Shuyan Guan. Email: guanshuyan@jlau.edu.cn; Yiyong Ma. Email: m18404319202_1@126.com \\ Received: 25 February 2021 Accepted: 16 June 2021
}

\begin{abstract}
Immature embryos of inbred maize (Zea mays) lines (H8183, H8184, and H8185) were used for Agrobacterium infection. We used the $\beta$-glucuronidase gene (GUS) as the target gene and the glufosinate resistance gene (bar) as the selection marker. We conducted research on several aspects, such as different genotypes, coculture conditions, screening agent concentrations, and concentrations of indole-3-butytric acid (IBA), 6-benzylaminopurine (6-BA), and ascorbic acid (Vc) in the differentiation medium. We optimized the genetic transformation system, and the obtained results indicated that among the three lines studied, the induction rate of H8185 was the highest at 93.2\%, followed by H8184, with $\mathrm{H} 8183$ having the lowest induction rate $(80.1 \%)$. The best coculture method was that using the N6 coculture medium layered with a sterile filter paper. Using orthogonal analysis, we found that the optimal combination of the three factors in the differentiation medium was $\mathrm{A}_{3}\left(1 \mathrm{mg} \mathrm{mL} \mathrm{m}^{-1} \mathrm{IBA}\right), \mathrm{B}_{3} \mathrm{C}_{1}$ (1.6 mg mL $\mathrm{mL}^{-1}$ 6-BA), and $\mathrm{D}_{3}\left(1.5 \mathrm{mg} \mathrm{mL}^{-1} \mathrm{Vc}\right)$. Through GUS staining analysis, Bar test-strip analysis, and polymerase chain reaction, five transgenic plants were finally obtained. This study established the optimal conditions for genetic transformation in maize.
\end{abstract}

\section{KEYWORDS}

Maize; optimization; genetic; regeneration; immature embryos; Agrobacterium-mediated transformation

\section{Introduction}

Maize, Zea mays L. (Gramineae family), originated in South America and is a globally important food crop. With the recent increasing demand, genetic modification via plant genetic engineering has become of great significance toward yield and quality improvement. Although there are various transformation methods, the efficiency of maize transformation is typically low owing to the lack of stable and efficient tissue culture and plant regeneration systems. However, Agrobacterium-mediated transformation has been widely used in dicotyledonous plants since 1983, when Zambryski successfully obtained transgenic tobacco. However, the application range of this method is limited for monocots, which are unnatural hosts of Agrobacterium. Therefore, studying the conditions affecting maize tissue culture and Agrobacterium-mediated genetic transformation is essential for cultivating high-yield, high-quality, and stress-resistant novel maize varieties. 
In 1986, Graves et al. attempted to obtain transgenic maize by injecting Agrobacterium suspension in maize seedlings but failed to obtain transgenic plants [1]. Using the meristem of maize seedlings, Grimsley et al. injected Agrobacterium rhizogenes C58 containing Maize streak virus gene and observed viral replication in the nucleus [2]. Subsequently, Schlappi et al. used Agrobacterium to infect immature embryos and coleoptiles from four maize varieties and found that Agrobacterium-mediated transformation requires competent cells [3]. Ishida et al. [4] established an Agrobacterium-mediated genetic transformation system with a transformation efficiency of up to $30 \%$ using maize A188 immature embryos in 1996. This finding was hailed as a milestone in the history of Agrobacterium-mediated maize transformation. However, such high transformation efficiency can only appear in A188, and the disease resistance of this variety is extremely poor. Hence, the promotion value of this variety is limited. Wang et al. [5] successfully obtained transgenic plants using a scalpel; the meristem of germinating was wounded and the seeds were cocultured with an Agrobacterium tumefaciens strain harboring a $\mathrm{Ti}$ plasmid. Sidorov et al. [6] used internodes of maize KHL and L4 seedlings to induce callus formation using Agrobacterium-mediated transformation and obtain a higher conversion efficiency. Frame et al. [7] successfully obtained transgenic plants using maize HiLL and used an Agrobacterium-carrying diploid vector for infection. Thereafter, the conversion rates of three maize inbred lines, such as B104 and Ky21, were improved by improving culture medium components.

Agrobacterium-mediated transformation results in good target gene expression, stable heredity, and low operational costs, and is the main application method in plant transgenic technology research [8-10]. However, some researchers still find that the differentiation and regeneration ability of resistant callus obtained by Agrobacterium infection would be reduced even if immature maize embryos are used as starting materials. Water staining, vitrification, browning, and seedling stagnation in most resistant callus were particularly serious limitations in the transformation stage [11,12]. Callus differentiation and rooting is unideal, which directly affects the survival rate of regenerated plants, making transgenic maize technology impossible. Therefore, it is important to optimize the conditions involved in Agrobacterium infection. In this study, H8183, H8184, and H8185 maize inbred lines were used to preliminarily study some factors affecting the conversion efficiency and optimal conditions of Agrobacterium transformation in maize callus. We attempted to improve the efficiency of genetic transformation in maize and lay the foundation for cultivating novel maize germplasm resources in the future.

\section{Materials and Methods}

\subsection{Acquisition of Explants}

The test material seeds of maize inbred lines, H8183, H8184, and H8185, were sown in the experimental field of the Key Laboratory of Crop Molecular Breeding in Jilin Province. After artificial pollination, immature maize embryos were stripped by selecting 10-13-day-old, pollinated, female maize ears. The outer husk was stripped off (leaving only a layer of young leaves) and then the maize were soaked in $75 \%$ ethanol for $15 \mathrm{~min}$. Next, the young leaves and corn silk were removed. The remaining immature embryos were disinfected using $0.5 \% \mathrm{NaClO}$ for $10 \mathrm{~min}$ and then rinsed three or four times with sterile water. Finally, a scalpel was used to remove the seed coat and endosperm at the top of the ear and to pull out immature embryos. The immature embryos of H8183, H8184, and $\mathrm{H} 8185$ that were pollinated on

days 10-13 were then inoculated into the N6 induction medium. Every subsequent 2 weeks, stable callus were formed in approximately 40 days for subsequent infection and transformation.

\subsection{Strains and Vectors}

The Agrobacterium strain EHA105 harboring the empty vector pCAMBIA3301 preserved in our laboratory was used in this study (Fig. 1). The binary vector contains the $\beta$-glucosidase $(G U S)$ reporter 
gene and the herbicide resistance bar gene. Phosphinothricin acetyltransferase (PAT) encoded by the bar gene can inactivate phosphinothricin. Glufosinate-ammonium was used as a screening agent.

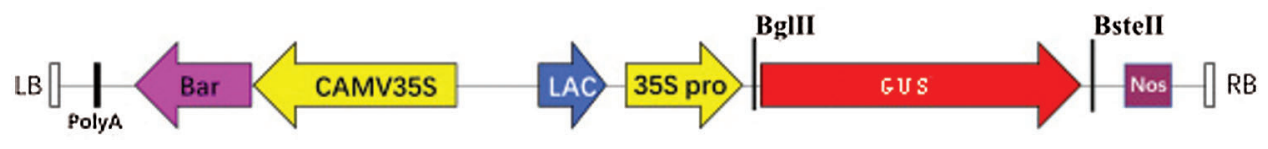

Figure 1: Plasmid map of pCAMBIA3301

\subsection{Preparation of Agrobacterium-Mediated Transformation Solution}

A single colony of Agrobacterium strain harboring the pCAMBIA3301 plasmid was selected and inoculated in YEP liquid medium containing appropriate antibiotics and incubated overnight on a shaker set at $28^{\circ} \mathrm{C}$ and $200 \mathrm{rpm}$. Bacteria were collected using centrifugation when OD600 reached 0.6. Following this, the bacterial pellet was resuspended in the infection solution (Agrobacterium-mediated transformation solution) containing $200 \mu \mathrm{mol} / \mathrm{L}$ acetosyringone (AS).

\subsection{Coculture of Explants and Agrobacterium}

Maize callus, precultured on the induction medium for 3 days, were used for Agrobacterium-mediated transformation. The maize callus and bacterial solution were poured into conical flasks and shaken using a shaker at $28^{\circ} \mathrm{C}$ and $80 \mathrm{rpm}$ for $20-30 \mathrm{~min}$. The bacterial solution was discarded and the callus were transferred to a Petri dish with 2-3 layers of filter paper to absorb any excess bacterial solution. Subsequently, two coculture methods were adopted: (1) The callus were incubated directly on a solid coculture medium in the dark at $25^{\circ} \mathrm{C}$ for $2-3$ days. (2) The callus were transferred to a solid coculture medium with a layer of sterile filter paper and incubated at $25^{\circ} \mathrm{C}$ for $2-3$ days.

\subsection{Screening of Resistant Callus}

After coculture, the callus were transferred to the first screening medium, containing $0,2,4$, or $6 \mathrm{mg} / \mathrm{L}$ glufosinate-ammonium (screening agent), for approximately 25 days. The callus from the first screening were then transferred into the corresponding screening medium for the second screening, which lasted for approximately 25 days. The survival and adventitious bud induction rates were calculated. The results were analyzed using GraphPad Prism v.7.0 (A scientific software officially launched by GraphPad).

\subsection{Differentiation of Callus}

The screened resistant callus were transferred to a differentiation medium (Tab. 1) containing different concentrations of additives and exposed to light at $25^{\circ} \mathrm{C}$ for $16 \mathrm{~h} / \mathrm{d}$. Each flask was inoculated with 10 callus from each group with five replicates, using three factors and four levels of orthogonal test. The data from nine groups were processed by the $\mathrm{L}_{9}\left(3^{4}\right)$ method, and the results were observed after the callus were differentiated into stems and leaves. The differentiation averages and differentiation rates of callus were also calculated.

\subsection{Rooting and Transplanting of Regenerated Plants}

Plants generated from callus differentiation were transplanted into a rooting medium post selection. When three to five long roots of approximately $5 \mathrm{~cm}$ were observed, the plants were cleaned for hydroponic culture. 
Table 1: Immature maize embryo callus differentiation in media containing different additive ratios

\begin{tabular}{llll}
\hline Test number & IBA $\left(\mathrm{mg} \mathrm{mL}^{-1}\right)$ & 6-BA $\left(\mathrm{mg} \mathrm{mL}^{-1}\right)$ & $\mathrm{Vc}\left(\mathrm{mg} \mathrm{mL}^{-1}\right)$ \\
\hline 1 & 0.6 & 1.6 & 0.5 \\
2 & 0.6 & 1.8 & 1.0 \\
3 & 0.6 & 2.0 & 1.5 \\
4 & 0.8 & 1.6 & 1.0 \\
5 & 0.8 & 1.8 & 1.5 \\
6 & 0.8 & 2.0 & 0.5 \\
7 & 1.0 & 1.6 & 1.5 \\
8 & 1.0 & 1.8 & 0.5 \\
9 & 1.0 & 2.0 & 1.0 \\
\hline
\end{tabular}

\subsection{Identification of Resistant Plants}

GUS staining was performed on young roots of the transplanted resistant regenerated plants. Before staining, the young roots were thoroughly washed with a phosphate buffer, following which they were stained according to the previously described GUS staining protocol [13]. The samples were placed in a $1.5-\mathrm{mL}$ centrifuge tube, followed by the addition of GUS staining solution (freshly prepared) until the samples were completely covered. The tubes were wrapped in aluminum foil and placed at $37^{\circ} \mathrm{C}$ overnight. Staining was observed under a microscope, and the instantaneous expression level of GUS gene was calculated (number of stained immature embryos/number of infected immature embryos).

Leaves from the transplanted putative transgenic plants were used for performing the Bar protein antibody test-strip analysis. Approximately $1 \mathrm{~cm}$ of the leaves was taken in a $1.5-\mathrm{mL}$ centrifuge tube and snap-frozen using liquid nitrogen; $0.4 \mathrm{~mL}$ extraction buffer was added, and the test paper was removed. The end of the strip marked with an indicator arrow was immersed in the buffer for 1 min. The expression of Bar protein was observed. CATB method [14] was used to extract maize genomic DNA, which was later used as a template for polymerase chain reaction (PCR). Specific primers for Bar-R: ATGAGCCCAGAACGACGCC and Bar-L: TCAAATCTCGGTGACGGGC were used for PCR. The PCR amplification cycle was as follows: predenaturation: $94^{\circ} \mathrm{C}$ for $5 \mathrm{~min}$; denaturation: $94^{\circ} \mathrm{C}$ for $30 \mathrm{~s}$; annealing: $58^{\circ} \mathrm{C}$ for $30 \mathrm{~s}$; extension: $72^{\circ} \mathrm{C}$ for $30 \mathrm{~s}, 35$ cycles; and extension: $72^{\circ} \mathrm{C}$ for $8 \mathrm{~min}$. After the reaction, the PCR products were detected using $1 \%$ agarose gel by electrophoresis. Accordingly, the number of transgenic plants was affirmed.

\section{Results}

\subsection{Effect of Different Inbred Maize Lines on Embryogenic Callus Produced Using Immature Embryos}

Three inbred lines, H8183, H8184, and H8185, were inoculated into the N6 medium to generate immature embryos after 10-13 days of pollination. The immature embryos from all three lines produced type II embryogenic callus with yellow or milky white, dry, rice-like grain structure. The number of callus obtained from each line was different. Fig. 2 shows the callus of the three inbred lines after one successive generation. According to the results of repeated experiments, the induction rate of the three genotypes was $\mathrm{H} 8185>\mathrm{H} 8183>\mathrm{H} 8184$. The recovery rate of $\mathrm{H} 8185$ was the highest at approximately 93.2\%. The recovery rates of $\mathrm{H} 8183$ and $\mathrm{H} 8184$ were very similar, $82.7 \%$ and $80.1 \%$, respectively (Tab. 2). 


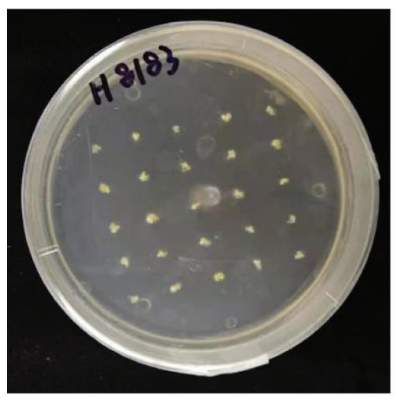

$A_{1}$

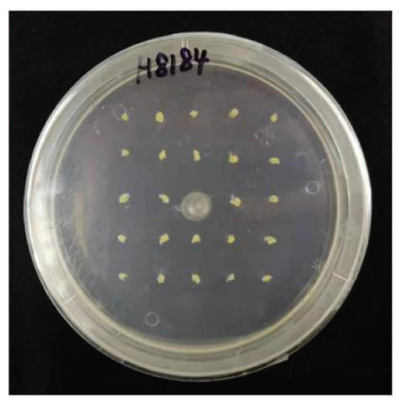

$\mathrm{B}_{1}$

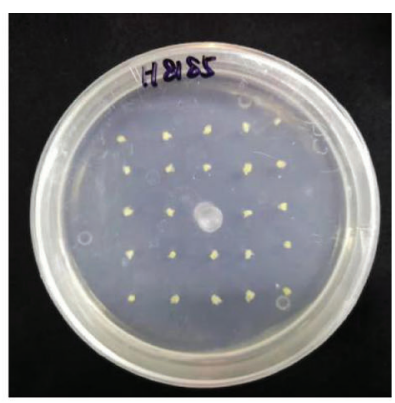

$\mathrm{C}_{1}$

Figure 2: Growth status of immature embryos from three maize inbred lines after one successive generation. $\mathrm{A}_{1}$ : inbred line H8183; $\mathrm{B}_{1}$ : inbred line H8184; $\mathrm{C}_{1}$ : inbred line H8185

Table 2: Recovery and callus induction in three maize inbred lines

\begin{tabular}{llll}
\hline Inbred lines & Recovery rate (\%) & $\begin{array}{l}\text { Induction rate of } \\
\text { type II callus (\%) }\end{array}$ & Callus growth \\
\hline H8183 & 82.7 & 66.5 & Faint yellow, less sprout, unloose \\
H8184 & 80.1 & 61.2 & Faint yellow, less sprout, unloose \\
H8185 & 93.2 & 85.7 & Golden yellow, many sprouts, \\
\hline
\end{tabular}

Note: The number of inoculations of different inbred lines is 500 per group.

\subsection{Influence of Coculture Conditions on the Bacteriostatic Effect}

After infection, the callus were cocultured either directly on a solid medium or on a solid medium with a layer of sterile filter paper. As observed in Fig. 3, the callus that were cocultured directly on a solid medium showed no plaque after 1 day, obvious plaque after 2 days, and a large area of plaque around the callus after 3 days. However, in the coculture method using a layer of sterile filter paper on the solid medium, no plaque appeared within 1-3 days. This indicates that coculture with filter paper-containing media can effectively reduce the growth of bacteria in the callus. The lower the Agrobacterium concentration, the more effectively the growth of bacteria carried by the explants can be reduced. Therefore, the method of using a solid medium with a layer of sterile filter paper for coculture has better antibacterial effects than that using a solid medium directly.

\subsection{Effect of the Content of Glufosinate-Ammonium on the Survival Rate of Callus and the Induction Rate of Adventitious Buds}

The cocultured callus were transferred to the first screening medium containing $0,2,4$, or $6 \mathrm{mg} / \mathrm{L}$ glufosinate-ammonium for preliminary culture screening. The selection medium without glufosinateammonium was used as a control, and the growth status was evaluated after 25 days. The selection medium containing $2 \mathrm{mg} / \mathrm{L}$ glufosinate-ammonium resulted in the highest survival rates of callus, reaching $82.4 \%$, and adventitious bud differentiation (Fig. 4). The selection medium containing $4 \mathrm{mg} / \mathrm{L}$ glufosinate-ammonium resulted in significantly decreased survival rates of callus, with less-differentiated adventitious buds. On the selection medium containing $6 \mathrm{mg} / \mathrm{L}$ glufosinate-ammonium, most of the callus were albino and eventually died. The growth was extremely weak, with only few differentiated adventitious buds. 


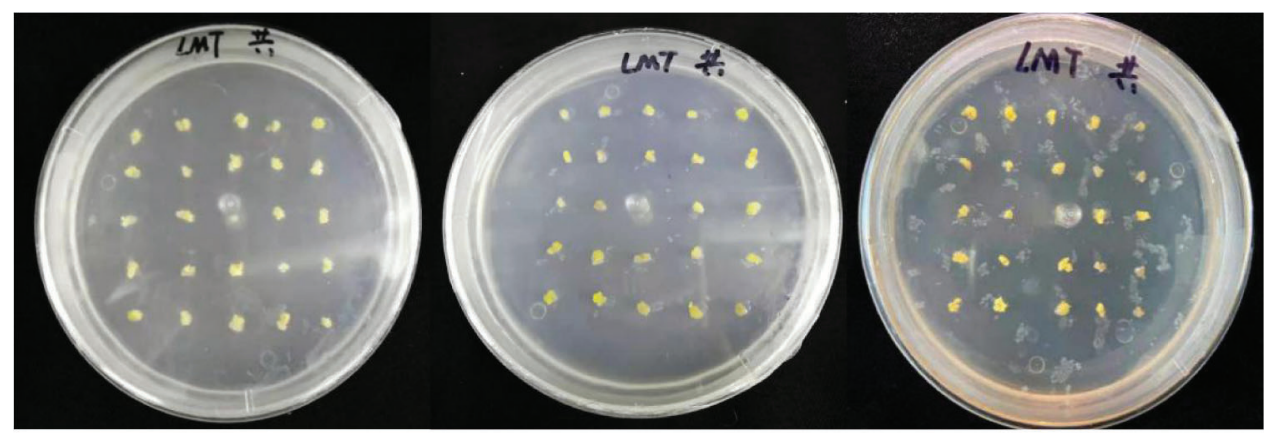

A2

B2

$\mathrm{C} 2$

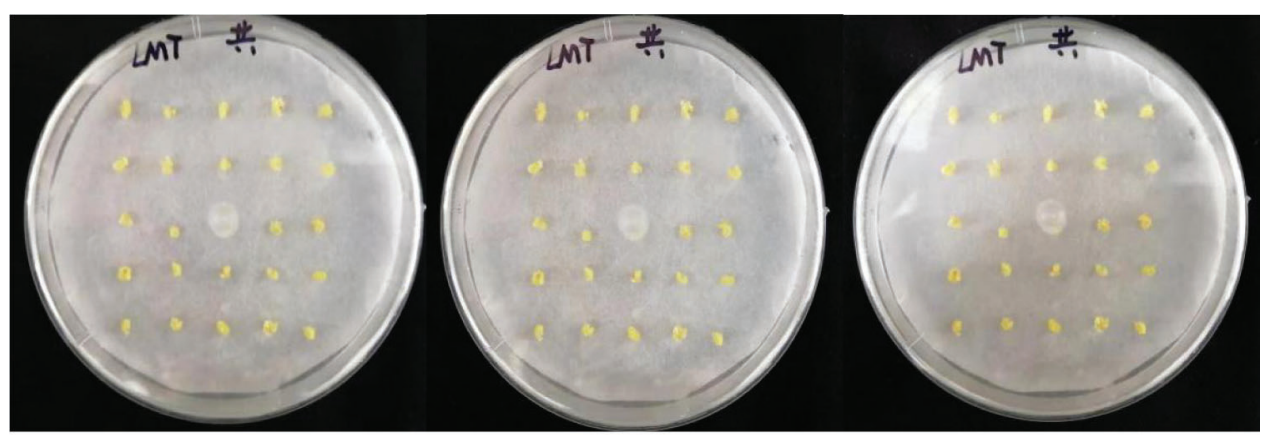

D2

E2

F2

Figure 3: Effects of the two coculture methods on bacterial infection in callus. $A_{2}-C_{2}$ : callus cocultured for 1-3 days without filter paper; $\mathrm{D}_{2}-\mathrm{F}_{2}$ : callus cocultured for $1-3$ days with filter paper

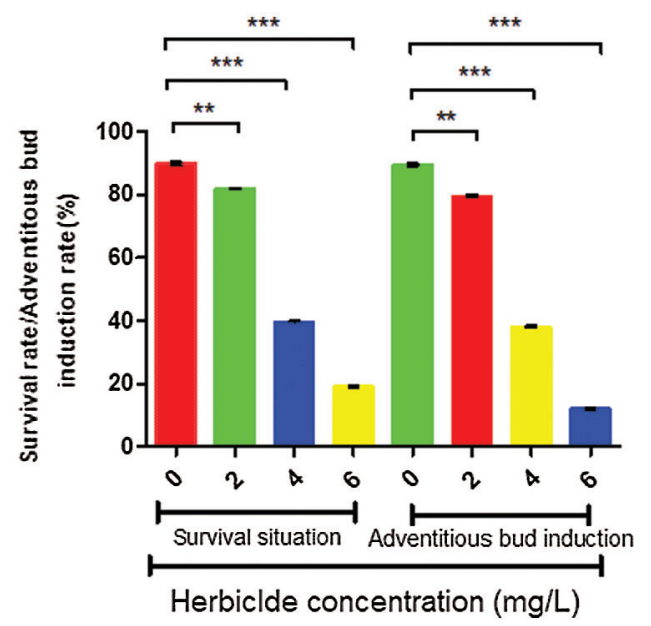

Figure 4: Effect of glufosinate-ammonium concentration on H8185 callus in the first screening

The callus selected on 2, 4, and $6 \mathrm{mg} / \mathrm{L}$ glufosinate-ammonium-supplemented medium were transferred to the corresponding secondary selection medium, and the survival and adventitious bud induction rates were evaluated. When the concentration of glufosinate-ammonium was 0 and $2 \mathrm{mg} / \mathrm{L}$, the survival rate of the callus was $>70 \%$, and the explants grew well. However, with the increase in glufosinate-ammonium concentration, the survival rate of callus and the induction rate of adventitious buds gradually decreased (Fig. 5). When the concentration of glufosinate-ammonium was $4 \mathrm{mg} / \mathrm{L}$, some explants could not 
differentiate into callus, but the adventitious bud induction rate could still reach $41.8 \%$. When the concentration of glufosinate-ammonium was $6 \mathrm{mg} / \mathrm{L}$, most of the callus appeared yellow, and the adventitious bud induction rate was $<10 \%$. These results indicated that $6 \mathrm{mg} / \mathrm{L}$ glufosinate-ammonium had an inhibitory effect on maize callus and inhibited adventitious bud induction. Therefore, in the screening process, the first screening medium containing $2 \mathrm{mg} / \mathrm{L}$ glufosinate-ammonium was used, followed by the second screening medium containing $4 \mathrm{mg} / \mathrm{L}$ glufosinate-ammonium, which could ensure the normal germination of transformed callus and reduce the generation of escaped buds.

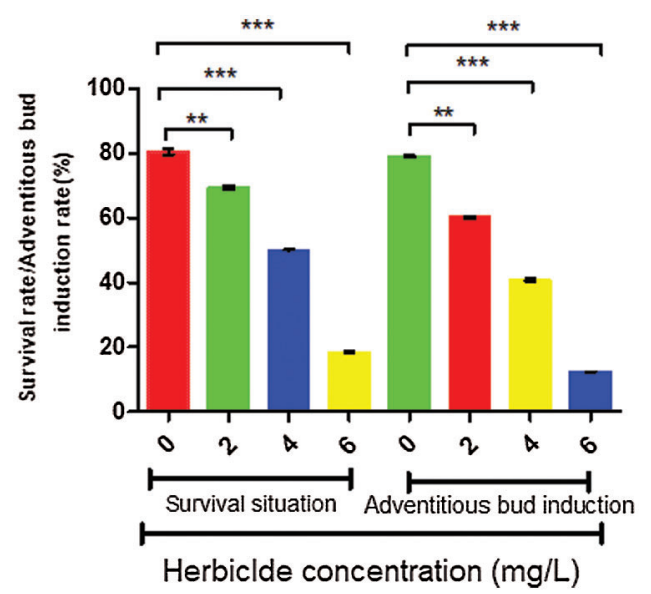

Figure 5: Effect of glufosinate-ammonium concentration on H8185 callus in the second screening

\subsection{The Influence of Different Differentiation Media on bud Differentiation}

To further study the relationship between the factors affecting the differentiation rate in maize callus and the relative intensity of the influence of each factor on the differentiation rate of maize callus, the $\mathrm{L}_{9}\left(3^{4}\right)$ orthogonal test was used to design different differentiation combinations. Results showed that the differentiation rate of callus changed depending on the changes in the three factors (Tab. 3). The value of range " $R$ " intuitively reflects the degree of influence of each factor on the differentiation rate of maize callus. The greater the $\mathrm{R}$ value, the greater the degree of influence; accordingly, the smaller the $\mathrm{R}$ value, the smaller the effect. According to the $R$ value, the influence of various factors on the differentiation rate of maize callus in this study was as follows: IBA concentration (A) $>6$-BA concentration (C) $>\mathrm{Vc}$ concentration (D).

According to the average callus differentiation rate at each level of each factor, the optimal level of each factor was determined as A3 (1 mg mL $\left.\mathrm{mL}^{-1} \mathrm{IBA}\right), \mathrm{B} 3 \mathrm{C} 1\left(1.6 \mathrm{mg} \mathrm{mL}^{-1}\right.$ 6-BA), and $\mathrm{D} 3\left(1.5 \mathrm{mg} \mathrm{mL}^{-1} \mathrm{Vc}\right)$. The results of variance analysis (Tab. 4) revealed that there was no significant difference between the third group, while the seventh, eighth, and other remaining groups showed a significant difference. The seventh group had the most optimized combination, which was A3B3C1D3, and the corresponding concentrations were $1 \mathrm{mg} \mathrm{mL}^{-1}$ IBA, $1.6 \mathrm{mg} \mathrm{mL}^{-1}$ 6-BA, and $1.5 \mathrm{mg} \mathrm{mL}^{-1} \mathrm{Vc}$.

\section{Identification of Transgenic Plants}

\subsection{GUS Histochemical Staining Analysis}

GUS histochemical staining was performed on the roots of the putative transgenic plants. Partial staining results are presented in Fig. 6 . The roots of the resistant plants were stained blue to varying degrees, while the roots of nontransgenic plants were not stained. A total of 23 plant roots were used for staining, of which 13 were successfully stained, and the transient expression rate of GUS reached $55.9 \%$. This indicates that the GUS gene was integrated into maize and can be expressed stably. 
Table 3: Range analysis of the differentiation rate of $\mathrm{H} 8185$ callus

\begin{tabular}{|c|c|c|c|c|c|}
\hline $\begin{array}{l}\text { Test } \\
\text { number }\end{array}$ & $\begin{array}{l}\text { IBA } \\
\left(\mathrm{mg} \mathrm{mL}^{-1}\right)\end{array}$ & $\begin{array}{l}\text { Blank } \\
\text { column }\end{array}$ & $\begin{array}{l}\text { 6-BA } \\
\left(\mathrm{mg} \mathrm{mL}^{-1}\right)\end{array}$ & $\begin{array}{l}\mathrm{Vc} \\
\left(\mathrm{mg} \mathrm{mL}^{-1}\right)\end{array}$ & $\begin{array}{l}\text { Differentiation } \\
\text { rate }\end{array}$ \\
\hline 1 & 1 & 1 & 1 & 1 & 64 \\
\hline 2 & 1 & 2 & 2 & 2 & 57 \\
\hline 3 & 1 & 3 & 3 & 3 & 68 \\
\hline 4 & 2 & 1 & 2 & 3 & 47 \\
\hline 5 & 2 & 2 & 3 & 1 & 49 \\
\hline 6 & 2 & 3 & 1 & 2 & 55 \\
\hline 7 & 3 & 1 & 3 & 2 & 65 \\
\hline 8 & 3 & 2 & 1 & 3 & 69 \\
\hline 9 & 3 & 3 & 2 & 1 & 58 \\
\hline K1 & 1.89 & 1.76 & 1.88 & 1.71 & \\
\hline $\mathrm{K} 2$ & 1.51 & 1.75 & 1.62 & 1.77 & \\
\hline $\mathrm{K} 3$ & 1.92 & 1.81 & 1.81 & 1.84 & \\
\hline K1 & 0.63 & 0.59 & 0.63 & 0.57 & \\
\hline $\mathrm{K} 2$ & 0.5 & 0.58 & 0.54 & 0.59 & \\
\hline K3 & 0.64 & 0.60 & 0.61 & 0.61 & \\
\hline $\mathrm{R}$ & 0.14 & 0.02 & 0.09 & 0.04 & \\
\hline Main order of factors & & & $\mathrm{A}>\mathrm{C}>\mathrm{D}>\mathrm{B}$ & & \\
\hline Optimal level & A3 & B3 & $\mathrm{C} 1$ & D3 & \\
\hline Optimal combination & & & $\mathrm{A}_{3} \mathrm{~B}_{3} \mathrm{C}_{1} \mathrm{D}_{3}$ & & \\
\hline
\end{tabular}

Note: Numbers in parentheses represent the concentration of the corresponding hormone.

$K$ value: Corresponding level under each factor.

$R$ value: $R=K \max -K \min$.

Table 4: Variance analysis of the differentiation rate of $\mathrm{H} 8185$ callus

\begin{tabular}{llllll}
\hline \multirow{2}{*}{ Test number } & \multicolumn{2}{l}{ Callus differentiation rate $(\%)$} & Standard deviation & Significant degree \\
\cline { 2 - 3 } & I & II & III & & $1 \%$ \\
\hline 1 & 59 & 66 & 67 & 0.0436 & C \\
2 & 53 & 53 & 65 & 0.0693 & D \\
3 & 66 & 69 & 69 & 0.0173 & B \\
4 & 43 & 52 & 46 & 0.0458 & G \\
5 & 55 & 49 & 43 & 0.0600 & E \\
6 & 58 & 54 & 53 & 0.0265 & F \\
7 & 66 & 68 & 61 & 0.0361 & A \\
8 & 74 & 67 & 66 & 0.0436 & B \\
9 & 57 & 59 & 58 & 0.0100 & CD \\
\hline
\end{tabular}




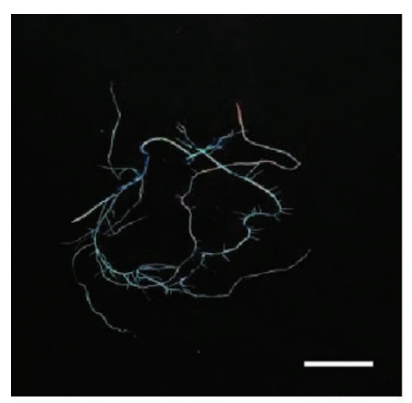

$\mathrm{A}_{3}$

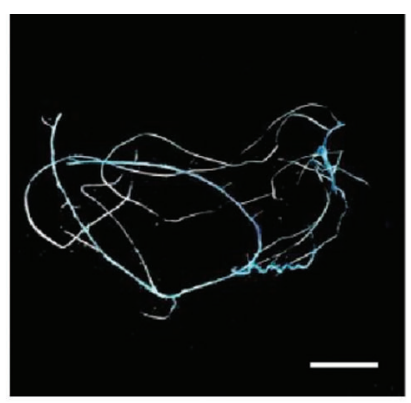

$\mathrm{B}_{3}$

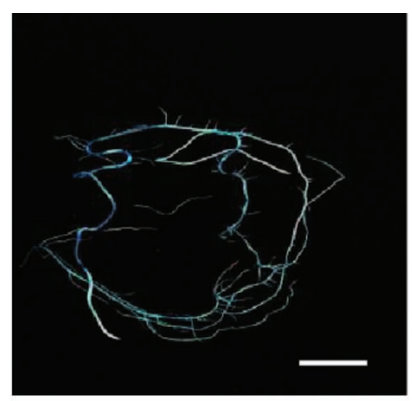

$\mathrm{C}_{3}$

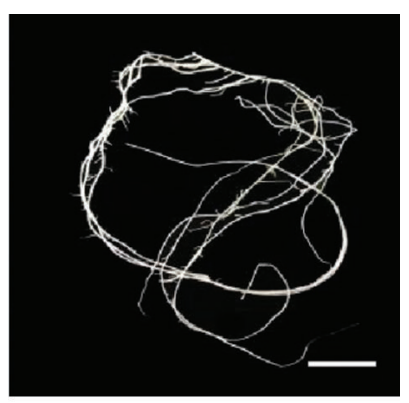

$\mathrm{D}_{3}$

Figure 6: GUS histochemical staining in maize. $\mathrm{A}_{3}-\mathrm{C} 3$ : transgenic plant; D3: control. Scale bar $=1 \mathrm{~cm}$

\subsection{PCR and Test-Strip Analysis for the Detection of Resistant Plants}

Genomic DNA of putative transgenic plants was extracted, and the bar gene was detected using PCR, with nontransgenic wild-type as a control. The target band was amplified only in the resistant transgenic plants, indicating that the obtained resistant regenerated materials were transgenic plants (Fig. 7). To further test whether the target gene introduced into the maize genome was expressed at the protein level, the resistant plants were tested using Bar test-strip analysis (Fig. 8), and finally five transgenic plants were obtained.

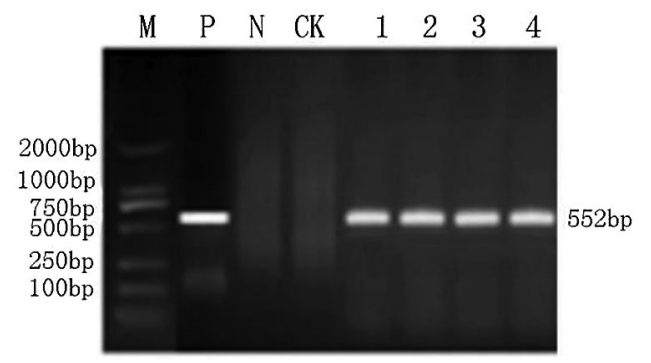

Figure 7: Results of Bar gene polymerase chain reaction in regenerated maize. M: DNA Marker DL 2000; P: 552 bp bar gene (positive control); $\mathrm{N}$ : $\mathrm{H}_{2} \mathrm{O}$ (negative control); $\mathrm{CK}$ : control plant; 1-4: transgenic plant

\section{Discussion}

Agrobacterium-mediated genetic transformation of maize is affected by many factors, including genotype, sampling site, preculture days, coculture conditions, and screening agent concentration. He et al. [15] believe that maize genotypes are important factors in determining in vitro responses. There are great differences in the regeneration ability of different genotypes, and adding different additives to the medium is a crucial factor for success. In this experiment, Agrobacterium-mediated genetic transformation was performed in immature embryos of three maize inbred lines, H8183, H8184, and H8185, and the results revealed that $\mathrm{H} 8185$ had the highest induction efficiency. This finding is consistent with the results reported by Raji et al., showing that different maize varieties have different transformation efficiencies following Agrobacterium infection [16]. Coculture stage is the key stage of Agrobacterium infection and transformation, and different coculture conditions directly affect the success of transformation, thereby affecting the transformation efficiency in maize. In this study, infected callus were either directly cocultured on a solid medium or on a solid medium with a layer of sterile filter paper. The results showed that the latter coculture method was better. Because sterile filter paper can keep the callus in a relatively dry state, it can better inhibit over-growth of Agrobacterium. At the end of the 
coculture, the callus need to be transferred to a screening medium for resistance screening to obtain resistant transformants; thus, it is necessary to determine the concentration of screening agents required for obtaining resistant plants [17]. If the concentration of the screening agent is high, it would be difficult to obtain transgenic plants, which results in difficulties in establishing genetic transformation systems. If the concentration of the screening agent is low, the false positive rate will be high and subsequent screening and identification work will be increased [18]. In this study, by comparing the survival and adventitious bud induction rates of callus in different media containing screening agents, the gradient screening method involving the use of $2 \mathrm{mg} / \mathrm{L}$ glufosinate-ammonium for first screening and $4 \mathrm{mg} / \mathrm{L}$ glufosinateammonium for second screening was established, which lays the foundation for follow-up experiments. Different concentrations of IBA, 6-BA, and Vc added to the differentiation medium had positive effects on callus differentiation [19]. Zhang et al. [20] suggested that the most suitable 6-BA concentration for wild wheat was $0.5 \mathrm{mg} / \mathrm{L}$, and a higher 6-BA concentration would increase the browning rate and decrease the callus differentiation rate, which could be because of the varying tolerance levels of crops to hormones. Sansar et al. [21] found that the combination of IBA and 6-BA had the best effect on adventitious bud proliferation in Poplar xinjiangensis, and the bud proliferation ratio was the best when 6-BA and NAA were used in combination for bud proliferation in Scutellaria stems [22]. In this study, orthogonal test was used to calculate the optimal combination of each additive in the differentiation medium: $\mathrm{A}_{3}\left(1 \mathrm{mg} / \mathrm{mL}\right.$ IBA), $\mathrm{B}_{3} \mathrm{C}_{1}\left(1.6 \mathrm{mg} / \mathrm{mL}\right.$ 6-BA), and $\mathrm{D}_{3}(1.5 \mathrm{mg} / \mathrm{mL} \mathrm{Vc})$, which further lays the foundation for improving the efficiency of genetic transformation in maize.

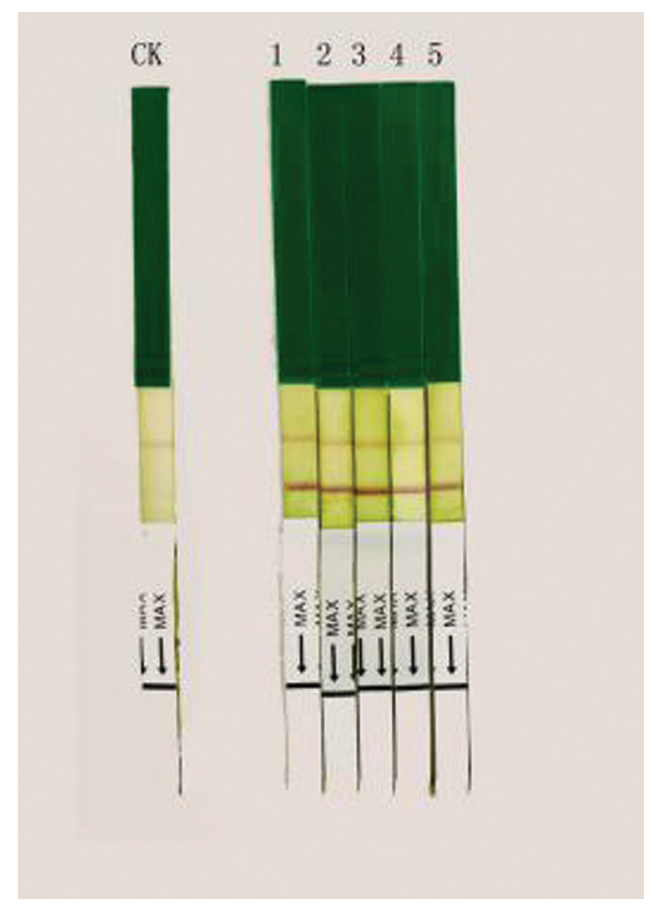

Figure 8: Bar test-strip analysis of transgenic plants. CK: control; 1-5: transgenic plants

\section{Conclusion}

At the embryogenic callus induction stage, induction rate and regeneration ability is controlled by genetic factors. Different genotypes showed varying results, but the inbred line H8185 was the most successful at callus production following embryo induction. Adding a layer of sterile filter paper on the solid medium used for coculture has good bacteriostatic effects. In the screening stage of resistant callus, 
the optimal screening gradient involved using $2 \mathrm{mg} / \mathrm{L}$ glufosinate-ammonium for the first screening and $4 \mathrm{mg} / \mathrm{L}$ glufosinate-ammonium for the second screening. According to the callus differentiation rates obtained using different factors at various levels, the optimal levels of these factors in the differentiation medium were as follows: $\mathrm{A}_{3}\left(1 \mathrm{mg} / \mathrm{mL}\right.$ IBA), $\mathrm{B}_{3} \mathrm{C}_{1}(1.6 \mathrm{mg} / \mathrm{mL} 6-\mathrm{BA})$, and $\mathrm{D}_{3}(1.5 \mathrm{mg} / \mathrm{mL} \mathrm{Vc})$. Genetic transformation has evolved into an efficient approach that improves maize yield, quality, and tolerance to biotic and abiotic stresses. This study provides an efficient genetic transformation method for maize, which could be useful for both tissue culture and crop improvement strategies in the future.

Acknowledgement: We thank Liwen Bianji (Edanz) (https://www.liwenbianji.cn) for editing the language of a draft of this manuscript.

Funding Statement: This work was supported by Jilin Provincial Natural Science Foundation Project [20190201168JC], "Thirteenth Five-Year" Science and Technology Project of Jilin Provincial Department of Education [JJKH20200341KJ], Science and Technology Project of Jilin Provincial Department of Education [JJKH20210351KJ, JJKH20210346KJ] Jilin Province Science and Technology Development Plan Project [20200402023NC], Jilin Province Key Technology R\&D Project [20180201029NY] and Jilin Province Support for the Science and Technology Development Program [20190802012ZG], College Student Innovation and Entrepreneurship Training Program Project [202010193087]. Furthermore, the funding body have no role in designing of study, collection and interpretation of data or writing up the manuscript.

Conflicts of Interest: The authors declare that they have no conflicts of interest to report regarding the present study.

\section{References}

1. Graves, A. E., Goldman, S. L., Banks, S. W., Graves, A. C. (1988). Scanning electron microscope studies of agrobacterium tumefaciens attachment to Zea mays, gladiolus sp., and Triticum aestivum. Journal of Bacteriology, 170(5), 2395-2400. DOI 10.1128/jb.170.5.2395-2400.1988.

2. Grimsley, N., Hohn, B., Ramos, C., Kado, C., Rogowsky, P. (1989). DNA transfer from Agrobacterium to Zea mays or brassica by agroinfection is dependent on bacterial virulence functions. Molecular and General Genetics, 217(2-3), 309-316. DOI 10.1007/BF02464898.

3. Schlappi, M. (1992). Competence of immature maize embryos for Agrobacterium-mediated gene transfer. Plant Cell Online, 4(1), 7-16. DOI 10.2307/3869377.

4. Ishida, Y., Saito, H., Ohta, S., Hiei, Y., Komari, T. et al. (1996). High efficiency transformation of maize (Zea mays L.) mediated by Agrobacterium tumefaciens. Nature Biotechnology, 14(6), 745-750. DOI 10.1038/ nbt0696-745.

5. Wang, J., Sun, Y., Li, Y. (2007). Maize (Zea mays) genetic transformation by co-cultivating germinating seeds with Agrobacterium tumefaciens. Biotechnology and Applied Biochemistry, 46(Pt 1), 51-55. DOI 10.1042/ BA20060065.

6. Sidorov, V., Gilbertson, L., Addae, P., Duncan, D. (2006). Agrobacterium-mediated transformation of seedlingderived maize callus. Plant Cell Reports, 25(4), 320. DOI 10.1007/s00299-005-0058-5.

7. Frame, B. R., Mcmurray, J. M., Fonger, T. M., Main, M. L., Taylor, K. W. et al. (2006). Improved Agrobacteriummediated transformation of three maize inbred lines using ms salts. Plant Cell Reports, 25(10), 1024-1034. DOI 10.1007/s00299-006-0145-2.

8. Yuan, H., Hou, H., Huang, T., Zhou, Z., Wang, L. (2021). Agrobacterium tumefaciens-mediated transformation of coniella granati. Journal of Microbiological Methods, 182, 106149. DOI 10.1016/j.mimet.2021.106149. 
9. Villena, C. I. F., Gomes, R. R., Fernandes, L., Florencio, C. S., Vicente, V. A. (2020). Agrobacterium tumefaciensmediated transformation of Fonsecaea monophora and Fonsecaea erecta for host-environment interaction studies. Journal of Fungi-Open Access Mycology Journal, 6(4), 325. DOI 10.3390/jof6040325.

10. Chowdhury, S. R., Hoque, S., Akter, N. (2020). Optimization of regeneration and Agrobacterium tumefaciensmediated transient transformation systems for Australian native extremophile, Tripogon loliiformis. Journal of King Saud University-Science, 32(8), 3476-3485. DOI 10.1016/j.jksus.2020.10.010.

11. Al-Ramamneh, E. A., Sriskandarajah, S., Serek, M. (2006). Agrobacterium tumefaciens-mediated transformation of rhipsalidopsis gaertneri. Plant Cell Reports, 25(11), 1219-1225. DOI 10.1007/s00299-006-0190-x.

12. Wang, J., Liu, S., Ma, H., Tao, Y., Feng, S. et al. (2020). Reliable and efficient Agrobacterium tumefaciens -mediated genetic transformation of Dianthus spiculifolius. Horticultural Plant Journal, 6(3), 199-204. DOI 10.1016/ j.hpj.2020.03.004.

13. Jefferson, R. A. (1987). Gus fusions: Beta-glucuronidase as a sensitive and versatile gene fusion marker in higher plants. Embo Journal, 6, 3901-3907. DOI 10.1002/j.1460-2075.1987.tb02730.x.

14. Sal, D., Manoletti, G. G., Schnieder, C. (1989). The CTAB-dNA precipitation method: A common mini-scale preparation of template DNA from phagemids, phages or plasmids suitable for sequencing. Biotechniques, 7 , 514-520. DOI 10.1002/bmc.1130030310.

15. Wang, J., Zhang, M., Dong, R., Liu, C., He, C. (2019). Heterologous expression of ZmGS5 enhances organ size and seed weight by regulating cell expansion in Arabidopsis thaliana. Gene, 793(3), 145749. DOI 10.1016/j. gene.2021.145749.

16. Raji, J. A., Frame, B., Little, D., Santoso, T. J., Wang, K. (2018). Agrobacterium- and biolistic-mediated transformation of maize B104 inbred. Methods in Molecular Biology, 1676, 15-40. DOI 10.1007/978-1-4939-7315-6.

17. Mahto, B. K., Poonam, S., Rajam, M. V., Reddy, P. M., Swatismita, D. R. (2018). An efficient method for Agrobacterium-mediated genetic transformation of chilli pepper (Capsicum annuum L.). Indian Journal of Plant Physiology, 23, 1-9. DOI 10.1007/s40502-018-0389-1.

18. Li, X., Li, H., Zhao, Y., Zong, P., Piao, Z. (2021). Establishment of a simple and efficient Agrobacterium-mediated genetic transformation system to Chinese cabbage (Brassica rapa L. ssp. pekinensis). Horticultural Plant Journal, 7(2), 117-128. DOI 10.1016/j.hpj.2021.01.006.

19. Chen, H., Guo, A., Tan, S., Wang J., Gao, J. et al. (2019). Agrobacterium tumefaciens-mediated transformation of a hevein-like gene into asparagus leads to stem wilt resistance. PLoS One, 14(10), e0223331.11. DOI 10.1371/ journal.pone.0223331.

20. Dubrovna, O. V., Slivka, L. V. (2020). Optimization of Agrobacterium-mediated transformation of perspective winter wheat genotypes in vitro. Faktori Eksperimental Noi Evolucii Organizmiv, 26, 190-195. DOI 10.7124/ FEEO.v26.1264.

21. Aggarwal, G., Srivastava, D. K. (2015). Establishment of high frequency shoot regeneration system in himalayan poplar (Populus ciliata wall. ex Royle) from petiole explants using thidiazuron cytokinin as plant growth regulator. Journal of Forestry Research, 26(3), 651-656. DOI CNKI:SUN:LYYJ.0.2015-03-012.

22. Hwang, I. T., Lee, J. J., Lee, J., Paik, S. W., Kim, Y. H. (2015). Production of baicalin, baicalein, and wogonin on plant tissue culture of Scutellaria baicalensis. Korean Journal of Plant Resources, 28(4), 526-532. DOI 10.7732/ kjpr.2015.28.4.526. 